\title{
Coresistance to quaternary ammonium compounds in extended-spectrum beta-lactamase-producing Escherichia coli
}

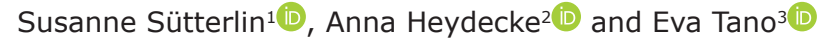 \\ 1. Department of Women's and Child's Health, International Maternal and Child Health, Uppsala University, Uppsala, \\ Sweden; 2. Center for Research and Development Gävleborg, Uppsala University, Gävle, Sweden; 3. Department of \\ Medical Sciences, Uppsala University, Uppsala, Sweden. \\ Corresponding author: Susanne Sütterlin, e-mail: susanne.sutterlin@kbh.uu.se \\ Co-authors: AH: anna.heydecke@regiongavleborg.se, ET: eva.tano@medsci.uu.se \\ Received: 06-05-2020, Accepted: 17-08-2020, Published online: 15-09-2020
}

doi: www.doi.org/10.14202/IJOH.2020.134-142 How to cite this article: Sütterlin S, Heydecke A, Tano E (2020) Coresistance to quaternary ammonium compounds in extended-spectrum beta-lactamase-producing Escherichia coli, Int. J. One Health, 6(2): 134-142.

\begin{abstract}
Background and Aim: Extended-spectrum $\beta$-lactamases (ESBL) in Escherichia coli constitutes one of the major threats to modern medicine, and the increasing pollution with quaternary ammonium compounds (QACs) has been suspected to contribute to the spread of ESBL-producing bacteria. The aim of the study was to investigate ESBL and ESBL $_{\mathrm{M}-\mathrm{C}}$ - $\mathrm{producing}$ E. coli isolates for their coresistance to QACs and their phylogeny isolated from a Swedish University Hospital.
\end{abstract}

Materials and Methods: Coresistance in E. coli with production of ESBL enzymes of the type bla $_{\text {СТХ-M }}$ (n=23) was compared to E. coli producing AmpC type ESBL enzymes $b l a_{\mathrm{CMY}}$ and $b l a_{\mathrm{DHA}}(\mathrm{n}=27)$. All isolates were tested for susceptibility to antibiotics and QACs, and high-quality whole-genome sequences were analyzed for resistance determinants.

Results: The plasmid-borne small multidrug resistance (SMR) efflux pump $\operatorname{sug} E(p)$ was solely present in $b l a_{\mathrm{CMY}}$-producing E. $\operatorname{coli}(\mathrm{n}=9)$, within the same genetic environment blaCMY-blc-sugE(p). Other small multidrug efflux pumps were found without association for ESBL-types: emrE $(\mathrm{n}=5)$ and the truncated qacE $\Delta l(\mathrm{n}=18)$.

Conclusion: Coresistance of ESBL enzymes and SMR efflux pumps in E. coli was common and might indicate that other substances than antibiotics contribute to the spread and emergence of antibiotic resistance.

Keywords: biocides, Escherichia coli, extended-spectrum $\beta$-lactamases, quaternary ammonium compounds.

\section{Introduction}

Antimicrobial resistance is an urgent global threat to public health with a high disease burden to humans [1]. Since the 2000s, public awareness has increased regarding the worrisome rapid spread of antibiotic resistance, and many efforts have been taken to slow this development down. Actions have been taken to combat well-known factors that drive antibiotic resistance, such as limit the overuse of antibiotics and improve hygiene in medical care, animal husbandry, and the community [2].

However, despite all efforts, the emergence and distribution of extended-spectrum $\beta$-lactamases (ESBL) in Escherichia coli and other Enterobacteriaceae that cause resistance to the $3^{\text {rd }}$-generation cephalosporins ESBL-producing $E$. coli continue, and therefore, other potential driving factors like the extensive use of biocides have been discussed. Concerns regarding the potential risk of biocidal substances have been raised early [3]. Especially, the intense use of substances that

Copyright: Sütterlin, et al. This article is an open access article distributed under the terms of the Creative Commons Attribution 4.0 International License (http://creativecommons.org/licenses/ by/4.0/), which permits unrestricted use, distribution, and reproduction in any medium, provided you give appropriate credit to the original author(s) and the source, provide a link to the Creative Commons license, and indicate if changes were made. The Creative Commons Public Domain Dedication waiver (http:// creativecommons.org/ publicdomain/zero/1.0/) applies to the data made available in this article, unless otherwise stated. belong to quaternary ammonium compounds (QACs) has frequently been stressed as a potential risk, especially as the effects of sublethal concentrations on bacterial populations are rather unknown $[4,5]$. They are heavily utilized as preservatives and fabric softeners and thus released in significant amounts into the water cycle [6]. Anthropogenic contamination of soils and water environments with QACs can significantly contribute to enrichment of mobile genetic elements involving resistance determinants to antibiotics and QACs $[7,8]$.

A majority of the clinically recognized ESBL enzymes have been mobilized from chromosomes of bacteria populating soils and other wet environments. Some ESBL enzymes became well-adapted in $E$. coli, such as bla $a_{\text {СТХ-M }}$ enzymes mobilized from Kluyvera spp., bla ${ }_{\mathrm{CMY}}$ enzymes from Citrobacter spp., or bla $a_{\mathrm{DHA}}$ from Morganella morganii, and they disseminate mainly through plasmids and certain bacterial clones $[9,10]$. Some of these plasmid-borne ESBL enzymes can be inhibited by beta-lactamase inhibitors, a fact that is used to classify ESBL enzymes in clinical contexts [11]. It distinguishes among others classical $\mathrm{ESBL}_{\mathrm{A}}$ (like $b l a_{\text {CTX-M }}$ ) that are inhibitable by beta-lactamase inhibitors and those that cannot be inhibited which are called miscellaneous $\mathrm{ESBL}_{\mathrm{M}-\mathrm{C}}$ (like $b l a_{\mathrm{CMY}}$ or $\left.b l a_{\mathrm{DHA}}\right)$; the latter are also known as plasmid-borne AmpC beta-lactamases.

Coresistance to bla $a_{\text {СТХ-M }}$ and biocides has been documented for QACs, in bacterial isolates involved in 
hospital outbreaks and environment $[12,13]$. However, this is less well studied for $\mathrm{ESBL}_{\mathrm{M}-\mathrm{C}}$. Against the background, that $\mathrm{ESBL}_{\mathrm{M}-\mathrm{C}}$-producing $E$. coli have become an emerging problem, it seems needful to study the coresistance potential of QACs to $\operatorname{ESBL}_{\mathrm{M}-\mathrm{C}}[10,14]$.

Thus, the aim of the study was to investigate $\mathrm{ESBL}_{\mathrm{A}}$ and $\mathrm{ESBL}_{\mathrm{M}-\mathrm{c}}$-producing E. coli isolates for their coresistance to QACs and their phylogeny isolated from a Swedish University Hospital.

\section{Materials and Methods \\ Ethical approval}

After retrieval of relevant information from the referral, all isolates were anonymized; therefore, no ethical approval was necessary.

\section{Bacterial isolates}

This study comprises a total of 58 urinary tract isolates producing ESBL enzymes that were collected between 2011 and 2016 at Uppsala University Hospital. Urinary tract samples were cultured quantitatively on blood agar plates and cystine-lactoseelectrolyte-deficient agar plates (Oxoid, UK), and species identification was done using standard laboratory procedures and automated species identifications systems Maldi TOF (Bruker Daltonics, USA). The study followed the recommendations of the Nordic Committee on Antimicrobial Susceptibility Testing (www.nordicast.org) for diagnostics and classification of ESBL enzymes: All isolates with reduced susceptibility to cefpodoxime were further investigated using a synergy test that assesses the inhibition of cefotaxime, ceftazidime, or cefepime by clavulanic acid. Beta-lactamases that can be inhibited by clavulanic acid classified as classical ESBL $\left(\mathrm{ESBL}_{\mathrm{A}}\right)$, and presumed enzymes that cannot be inhibited classified as suspicious plasmid-borne $\mathrm{AmpC}$ beta-lactamases $\left(\mathrm{ESBL}_{\mathrm{M}-\mathrm{C}}\right)$. Suspicious $\mathrm{ESBL}_{\mathrm{M}-\mathrm{C}}$ were further verified by polymerase chain reaction (PCR) for the presence of plasmid-borne enzymes of type $b l a_{\mathrm{CMY}}, b l a_{\mathrm{MOXM}}$, $b l a_{\mathrm{DHAM}}$ and $b l a_{\mathrm{ACCM}}$ (for details see below). All isolates were frozen as glycerol stock at $-80^{\circ} \mathrm{C}$.

For the purpose of this study, E. coli isolates originating from urinary tract samples producing $\mathrm{ESBL}_{\mathrm{A}}$ and $\mathrm{ESBL}_{\mathrm{M}-\mathrm{C}}$ were randomly chosen resulting in 30 isolates producing $\mathrm{ESBL}_{\mathrm{A}}$ and 28 isolates producing $\mathrm{ESBL}_{\mathrm{M}-\mathrm{C}}$. After excluding isolates originating from the same individual, 54 isolates were included in the study; thereafter, all isolates were anonymized.

\section{PCRs to distinguish ESBL $_{\mathrm{M}-\mathrm{C}}$}

Each PCR contained $1 \mu \mathrm{L}$ template DNA, $1 \mu \mathrm{L}$ of $10 \mu \mathrm{M}$ each primer, and HotStarTaq Master Mix Kit (Qiagen, Germany) to a final volume of $25 \mu \mathrm{L}$. The primers used had the following sequences with the expected size of the amplification product in parenthesis: bla ${ }_{\mathrm{ACCM}}$ forward 5'-AAC AGC CTC AGC AGC CGG TTA-3' and bla $a_{\mathrm{ACCM}}$ reverse 5'-TTC GCC GCA ATC ATC CCT AGC-3' (346 bp), bla ${ }_{\text {DHAM }}$ forward 5'-AAC TTT CAC AGG TGT GCT GGG T-3' and $b l a_{\text {DHAM }}$ reverse 5'-CCG TAC GCA TAC TGG CTT TGC-3' (405 bp), bla GAA CTG ACA GGC AAA-3' and bla $a_{\text {Сाтм }}$ reverse 5'-TTT CTC CTG AAC GTG GCT GGC-3' (462 bp), and bla $a_{\text {мохм }}$ forward 5'-GCT GCT CAA GGA GCA CAG GAT-3' and $b l a_{\text {Mохм }}$ reverse 5'-CAC ATT GAC ATA GGT GTG GTG C-3' 520 bp) [15]. Hafnia alvei CCUG $45642\left(b l_{\text {aACC }} \mathrm{M}\right)$, M. morganii CCUG $43604\left(b l_{\mathrm{aDHA}} \mathrm{M}\right)$, Citrobacter freundii CCUG 43597 $\left(b l_{\mathrm{aCIT}} \mathrm{M}\right)$, and Aeromonas hydrophila CCUG 30208 $\left(b l_{\text {amox }} \mathrm{M}\right)$ served as positive controls. The reaction mixtures were processed in a GeneAmp PCR System 9700 (Applied Biosystems, USA) with the following conditions: One cycle of $10 \mathrm{~min}$ at $94^{\circ} \mathrm{C} ; 35$ cycles of $60 \mathrm{~s}$ at $94^{\circ} \mathrm{C}, 60 \mathrm{~s}$ at $55^{\circ} \mathrm{C}$, and $60 \mathrm{~s}$ at $72^{\circ} \mathrm{C}$, respectively; one cycle of $8 \mathrm{~min}$ at $72^{\circ} \mathrm{C}$. Some $5 \mu \mathrm{L}$ of the PCR products were separated by gel electrophoresis on $1 \%$ agarose gel stained with GelRed (Biotium, USA) and compared with a molecular weight marker (Life Technologies, USA) after photographing in ultraviolet light.

\section{Susceptibility to QACs and antibiotics Antibiotics}

Antibiotic susceptibility testing was performed using disk diffusion methodology as recommended by NORDICAST (www.nordicast.org) and included the following antibiotics: Ampicillin, amoxicillin-clavulanic acid, piperacillin-tazobactam, mecillinam, cefadroxil, cephalexin, cefepime, cefotaxime, ceftazidime, ceftibuten, cefuroxime, ertapenem, meropenem, aztreonam, ciprofloxacin, gentamicin, tobramycin, tigecycline, nitrofurantoin, and trimethoprim. We categorized the isolates into susceptible, indeterminate, or resistant using the species-related breakpoints defined by NordicAST (version 7.0).

\section{$Q A C s$}

Susceptibility testing for biocides was performed by determining the minimal inhibition concentration (MIC) according to ISO 20776-1:2006 with the modification that ISO-Sensitest Broth (Oxoid, UK) was used. A microdilution assay with a final volume of $100 \mu \mathrm{L}$ was used to determine the MIC for the following substances (concentration ranges in parenthesis): Benzalkonium chloride (BAC, 4-128 mg/L) and cetyltrimethylammonium bromide (CTAB; 4-128 mg/L) (all Sigma-Aldrich, USA). All isolates with elevated MIC values (BAC $\geq 64 \mathrm{mg} / \mathrm{L}$ and $\mathrm{CTAB} \geq 64 \mathrm{mg} / \mathrm{L}$ ) were retested in macrodilution format $(1 \mathrm{~mL})$. Stock solutions were prepared freshly and inoculated with bacteria within $2 \mathrm{~h}$ after a serial dilution in respective range. A final inoculate of $5 \times 10^{5} \mathrm{CFU} / \mathrm{mL}$ was prepared from an overnight culture in $1.5 \mathrm{~mL}$ LuriaBertani broth (Sigma-Aldrich, USA) in room atmosphere at $35^{\circ} \mathrm{C}$. The MIC assays were incubated for $18-20 \mathrm{~h}$ in room atmosphere at $35^{\circ} \mathrm{C}$ and the MIC values were read as the lowest concentration yielding no visible growth. E. coli ATCC 25922, Enterobacter 
cloacae CCUG 38138, and Klebsiella pneumoniae ATCC 700603 were used as control strains.

\section{Whole-genome analysis}

DNA preparation and whole-genome sequencing

One colony of each isolate was incubated in $2 \mathrm{~mL} \mathrm{LB}$ broth (Sigma-Aldrich, USA) for $8 \mathrm{~h}$ at $37^{\circ} \mathrm{C}$ in room atmosphere. DNA preparation was done using a Wizard ${ }^{\circledR}$ Genomic DNA Purification Kit (Promega, USA) according to the manufacturer's recommendations for Gram-negative bacteria with the exception that DNA was rehydrated with $10 \mathrm{mM}$ Tris- $\mathrm{HCl}(\mathrm{pH} 8.0)$. The quality and quantity of the extracted DNA was controlled by gel electrophoresis, spectrophotometry (Nanodrop, Thermo Fisher), and Quant-iT dsDNA BR assay and a Qubit instrument (Invitrogen). After standardizing the DNA extracts, the samples were transferred to Oxford Genome Center for library preparation and whole-genome sequencing. Fragmented DNA was end-repaired, A-tailed, adapter-ligated, and amplified using Nextera DNA library Prep (Illumina, USA). Sequencing was done on an Illumina HiSeq4000 platform, generating 150 bp paired-end reads.

\section{Sequence analysis}

Paired-end reads of the isolates from all the datasets were assembled using VelvetOptimiser software (v2.2.4) with kmer lengths from 21 to 99 using default optimization functions. Species confirmation, determination of phylotypes, and multi-locus sequence typing were performed according to the seven gene Achtman scheme using the pipeline implemented in Enterobase [16]. A neighbor-joining tree was constructed for rMLST allele nucleotide sequences of the study isolates [17,18]. Concatenated sequences for the rMLST scheme were retrieved through BIGsDB, aligned with MAFFT (v7.271, https://mafft.cbrc.jp/ alignment/software/) and the tree was calculated using PHYLIP (v3.695, http://evolution.genetics.washington.edu/phylip.html). Paralogous loci were excluded (BACT000060, BACT000065) resulting in 51 concatenated ribosomal loci for the rMLST. The dataset was then bootstrapped 500 times with phylip seqboot followed by calculations of distance matrices with phylip dnadist and neighbor-joining trees with phylip neighbor and a consensus tree using phylip consense. Illumina short reads were mapped to the antimicrobial resistance determinants database ARG-Annot (version 3) and a custom gene database for known biocide-related resistance genes using srst2 (v0.2.0, https://github.com/katholt/srst2; supplementary material Table-S1). The result was interpreted as positive when the minimum coverage was over $90 \%$, maximum divergence under $10 \%$, and a maximum number of mismatches per read of 10 (default settings). All findings from short-read mapping were confirmed using nucleotide BLAST on draft genomes, using a word size of $10, \mathrm{match} / \mathrm{mismatch}$ scores of $1 /-2$, the gap cost was linear, and the filter was set for low complexity regions; results were considered positive when the identity of a hit was over $90 \%$ (https://blast. ncbi.nlm.nih.gov/). Replicon sites of suspected plasmids were typed using PlasmidFinder (www.genomicepidemiology.org, December 2019) and insertion sequences were determined using ISFinder (https:// www-is.biotoul.fr, December 2019). All data have been submitted to the European Nucleotide Archives and are available under the project reference number PRJEB17631, Table-S2 in the supplemental material for individual accession numbers.

\section{Statistical analysis}

The strength of the association between phenotypic resistance and resistance determinants was calculated with $\mathrm{R}$ and to each group, $\mathrm{ESBL}_{\mathrm{A}}$ and $\mathrm{ESBL}_{\mathrm{M}-\mathrm{C}}$ were determined with the odds ratio and $95 \%$ confidence intervals. Associations with $\mathrm{p}<0.05$ and a lower confidence interval $>1$ were considered as statistically significant. Graphical illustrations of the results were produced using the package ggplot2 as implemented R (R Foundation for Statistical Computing, Vienna, Austria, http://www.R-project.org/, version 3.4.4, 2018). The phylogenetic tree with metadata was illustrated using iTOL version 5 [19].

\section{Results}

\section{General comments on the datasets}

Three isolates were excluded from further analysis; in one case because of production of solely $b l a_{\mathrm{SHV}-12}$, and could, therefore, not be assigned to the groups of interest; and in two further isolates, no ESBL determinants could be found. Thus, the resulting group sizes were $n=23$ for $\mathrm{ESBL}_{\mathrm{A}}$ and $\mathrm{n}=27$ for $\mathrm{ESBL}_{\mathrm{M}-\mathrm{C}}$; and another isolate that had both $\mathrm{ESBL}_{\mathrm{A}}$ and $\mathrm{ESBL}_{\mathrm{M}-\mathrm{C}}$ enzymes $\left(b l a_{\text {CTX-M-14 }}\right.$ and $\left.b l a_{\mathrm{CMY}-2}\right)$. Within the isolate group, $\mathrm{ESBL}_{\mathrm{A}}$ enzymes of CTX-M-type were found: $b l a_{\text {СТХ-м-15 }}(\mathrm{n}=18), b l a_{\text {СТХ-M-27 }}(\mathrm{n}=3), b l a_{\text {СТХ-M-1 }}(\mathrm{n}=2)$, $b l a_{\text {CTX-M-14 }}(\mathrm{n}=1)$, and $b l a_{\text {CTX-M-8 }}(\mathrm{n}=1)$. The isolates within group $\mathrm{ESBL}_{\mathrm{M}-\mathrm{C}}$ produced beta-lactamases of type $b l a_{\mathrm{CMY}-2}(\mathrm{n}=21)$, bla $_{\mathrm{CMY}-42}(\mathrm{n}=1)$, and $b l a_{\mathrm{DHA}-1}(\mathrm{n}=5)$.

\section{Sequence data}

Species verification on sequence data using the Enterobase pipeline confirmed the purity of the whole-genome extracts and that all isolates belonged to the species $E$. coli. The average coverage of the high-quality short reads from all collections was 118 (SD of \pm 74 ). Draft genomes were obtained for all included isolates resulting in a median contig number (>10,000 bp size) of 55 (range 36-179), the median N50 value was 171,769 (range 48,359-322,359), the median total length of nucleotides assembled in the draft genome ( $>0$ bp) was $5,179,586$ bp (range 4,677,941-9,341,633 bp).

\section{Comparison of $\mathrm{ESBL}_{\mathrm{A}}$ and $\mathrm{ESBL}_{\mathrm{M}-\mathrm{C}}$ Phylogeny}

All E. coli phylogroups were represented among the isolates; and the phylogroups were dominated by 
certain clonal complexes that are frequently associated with extra-intestinal manifestations. Within phylogroup B2, the clonal complex of sequence type 131 (CC ST131) dominated $(12 / 51 ; 24 \%)$, in phylogroup A, clonal complex ST10 (CC ST10) was most often found $(8 / 51$; $16 \%$ ), and correspondingly in phylogroup $\mathrm{C}$ dominated clonal complex ST23 (5/51; 10\%). For phylogroup D, both clonal complex ST69 (CC ST69) and ST38 (CC ST38) were represented with three $(3 / 51,6 \%)$ and four isolates $(4 / 51,8 \%)$, respectively. The odds that isolates producing $\mathrm{ESBL}_{\mathrm{M}-\mathrm{C}}$ were part of one of the phylogroups $\mathrm{A}, \mathrm{B} 1, \mathrm{C}, \mathrm{F}$, or D were $5.1(1.2-26.8, \mathrm{p}=0.01)$; this trend was true for all of these phylogroups, however, only statistically significant for phylogroup A (odds ratio 8.9 [1.0-428.3], $\mathrm{p}=0.03$ ). Hence, $\mathrm{ESBL}_{\mathrm{A}}$-producing isolates were associated to phylogroup B2 with an odds ratio of $5.1(1.2-26.8, \mathrm{p}=0.01)$ (Figure-1).

\section{Susceptibility testing} Antibiotics

Resistance to the penicillin ampicillin was high $(51 / 51 ; 100 \%)$, while the combination with beta-lactam inhibitors increased susceptibility for amoxicillin/clavulanic acid $(41 / 51 ; 80 \%)$ and piperacillin/ tazobactam $(2 / 51 ; 4 \%)$. Low resistance rates were seen for cephalosporins: Cefotaxime $(44 / 51 ; 86 \%)$, ceftazidime $(41 / 51 ; 80 \%)$, ceftriaxone $(43 / 51 ; 84 \%)$, cephalexin $(45 / 51 ; 88 \%)$, cefepime $(13 / 51 ; 25 \%)$, and ceftibuten $(32 / 51 ; 63 \%)$. The resistance rates for aminoglycosides varied for respective substances: Tobramycin $(19 / 51 ; 37 \%)$, gentamicin $(11 / 51 ; 22 \%)$, and amikacin $(1 / 51 ; 2 \%)$. Other commonly used antibiotics for urinary tract infections also had high resistance rates: Trimethoprim $(31 / 51 ; 61 \%)$, ciprofloxacin $(30 / 51 ; 59 \%)$, and nitrofurantoin $(3 / 51 ; 6 \%)$. None of the isolates was resistant to carbapenems or mecillinam. $\mathrm{ESBL}_{\mathrm{A}}$ isolates tended to have higher resistance rates compared to $\mathrm{ESBL}_{\mathrm{M}-\mathrm{C}}$ isolates regarding cefuroxime $\left(23 / 23(100 \%) \mathrm{ESBL}_{\mathrm{A}}\right.$ versus $11 / 27(41 \%)$

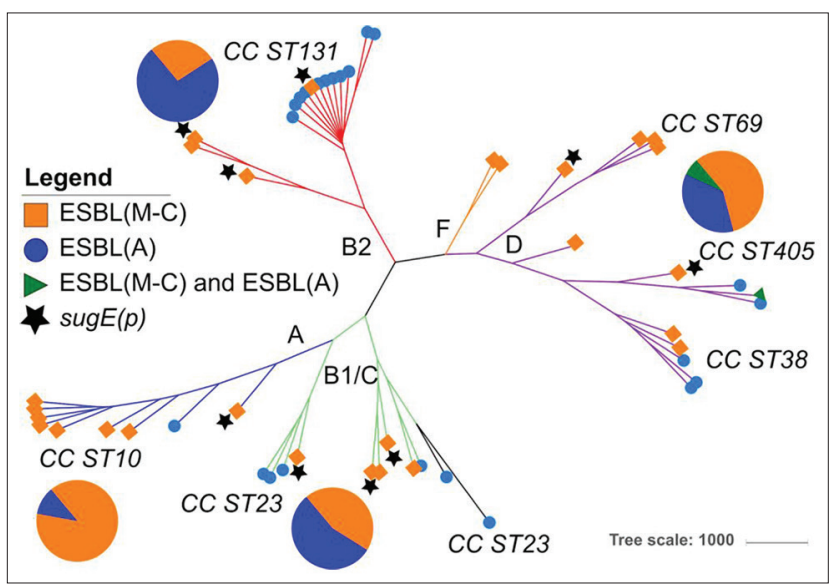

Figure-1: Network illustration for the study Escherichia coli isolates based on an rMLST neighbor-joining tree. Isolates with $\mathrm{ESBL}_{\mathrm{A}}$ (blue dots), $\mathrm{ESBL}_{\mathrm{M}-\mathrm{C}}$ (orange rectangles), both $\mathrm{ESBL}_{\mathrm{A}}$ and $\mathrm{ESBL}_{\mathrm{M}-\mathrm{C}}$ (green triangle), $\operatorname{sug} E(p)$ (black stars); phylogroups were illustrated by colored leaves: B2 (red), D (purple), A (blue), F (orange), B1/C (green).
$\left.\mathrm{ESBL}_{\mathrm{M}-\mathrm{C}}, \mathrm{p}<0.005\right)$ and aminoglycosides, especially tobramycin (16/23 [70\%] $\mathrm{ESBL}_{\mathrm{A}}$ vs. 3/27 [11\%] ESBL $\left._{M-C}, p<0.005\right)$. Conversely, ceftibuten had a higher resistance rate in $\mathrm{ESBL}_{\mathrm{M}-\mathrm{C}}$ isolates compared to $\operatorname{ESBL}_{\mathrm{A}}\left(25 / 27[92 \%] \mathrm{ESBL}_{\mathrm{M}-\mathrm{C}}\right.$ VS. 8/23 [35\%] $\mathrm{ESBL}_{\mathrm{A}}$, $\mathrm{p}<0.005$ ) (Figure-2).

\section{$Q A C s$}

The MIC ranges for $\mathrm{BAC}$ and for $\mathrm{CTAB}$ in all study isolates were $32-64 \mathrm{mg} / \mathrm{L}$. For the reference strains, the following MIC ranges for $\mathrm{BAC}$ were found: E. coli (ATCC25922) 16-32 mg/L, E. cloacae (CCUG38136) 32-64 mg/L, and K. pneumoniae (ATCC700603) 32-64 mg/L; and accordingly, E. coli (ATCC25922) 16-64 mg/L, E. cloacae (CCUG38136) $32-128 \mathrm{mg} / \mathrm{L}$, and $K$. pneumoniae (ATCC700603) $128-512 \mathrm{mg} / \mathrm{L}$ for CTAB. No difference was seen between both groups $\mathrm{ESBL}_{\mathrm{A}}$ and $\mathrm{ESBL}_{\mathrm{M}-\mathrm{C}^{\circ}}$

\section{Genetic resistance determinants}

Antibiotic resistance determinants

Besides ESBL, other beta-lactamases were detected: $b l a_{\mathrm{OXA}-1}$ that were only found in $\mathrm{ESBL}_{\mathrm{A}}-$ producing isolates $\left(15 / 23\right.$ [65\%] $\mathrm{ESBL}_{\mathrm{A}}$ vs. $0 / 27$ [0\%] ESBL $_{\mathrm{M}-\mathrm{C}} \mathrm{p}<0.005$ ); and TEM-1D beta-lactamases in 17 isolates, without a statistically significant distribution between the collections. The plasmid-borne quinolone resistance determinants $q n r B$ were found in five isolates and only in $\mathrm{ESBL}_{\mathrm{M}-\mathrm{C}}$-producing isolates, however, the association was not statistically significant. In contrast, the quinolone resistance determinant $a a c\left(6^{\prime}\right) \mathrm{Ib}-\mathrm{c} r$ was only found in $\mathrm{ESBL}_{\mathrm{A}}$ isolates $(14 / 23$ [61\%] ESBL $\mathrm{A}_{\mathrm{A}}$ vs. 0/27 [0\%] $\left.\mathrm{ESBL}_{\mathrm{M}-\mathrm{C},} \mathrm{p}<0.005\right)$. The macrolide 2' phosphor transferase I $m p h A$ was detected in 20 isolates and more often in $\mathrm{ESBL}_{\mathrm{A}}$-producing E. coli $\left(14 / 23[61 \%] \mathrm{ESBL}_{\mathrm{A}}\right.$ vs. $6 / 27\left[22 \% \mathrm{ESBL}_{\mathrm{M}-\mathrm{C}}\right.$, $\mathrm{p}<0.004)$. Aminoglycoside resistance determinants $a a c$ and $a a d$ were more often found in $\operatorname{ESBL}_{\mathrm{A}}(19 / 23$ [83\%] ESBL A $_{\mathrm{A}}$ vs. 6/27 [22\%] $\mathrm{ESBL}_{\mathrm{M}-\mathrm{C}}, \mathrm{p}<0.005$ ). Furthermore, chloramphenicol resistance determinant cat was only found in isolates with $\mathrm{ESBL}_{\mathrm{A}}$ production $\left(15 / 23[65 \%] \mathrm{ESBL}_{\mathrm{A}}\right.$ vs. $0 / 27\left[0 \% \mathrm{ESBL}_{\mathrm{M}-\mathrm{C}}\right.$, $\mathrm{p}<0.005$ ) (Figure-2).

\section{Biocidal resistance determinants}

The plasmid-borne small multidrug efflux pump $\operatorname{sug} E(p)$ was only found in $\mathrm{ESBL}_{\mathrm{M}-\mathrm{C}}$ isolates $(9 / 27$ [33\%] $\mathrm{ESBL}_{\mathrm{M}-\mathrm{C}}$ vs. 0/23 [0\%] $\left.\mathrm{ESBL}_{\mathrm{A}}, \mathrm{p}=0.002\right)$. All isolates positive to $\operatorname{sug} E(p)$ produced concomitantly $b l a_{\mathrm{CMY}-2}$ and $b l a_{\mathrm{CMY}-42}$, and the isolates were distributed within nearly all phylogenetic groups. In all $\operatorname{sug} E(p)$ positive isolates, the gene was found in the same genetic environment $b l a_{\mathrm{CMY}}-b l c-s u g E$ mostly with transposable insertion sequences. Four isolates had transposable elements that showed similarity to ISEcp1 (IS1380 family) and one had an ISSbol (IS91 family) that was assembled on a contig with an IncI1 replicon site. For two isolates, no insertion sequences were found, and in further two, it was an incomplete ISEcp1 (Figures-1 and 3). The 
multidrug efflux pump emrE was found in five isolates, and the truncated qacE $\triangle l$ was found in 18 isolates; no association was seen for ESBL-types.
The multidrug efflux pump determinants $\operatorname{acr} A B R$, emrAB, and acrEF (envCD), and the outer membrane channel tolC were present in all isolates.

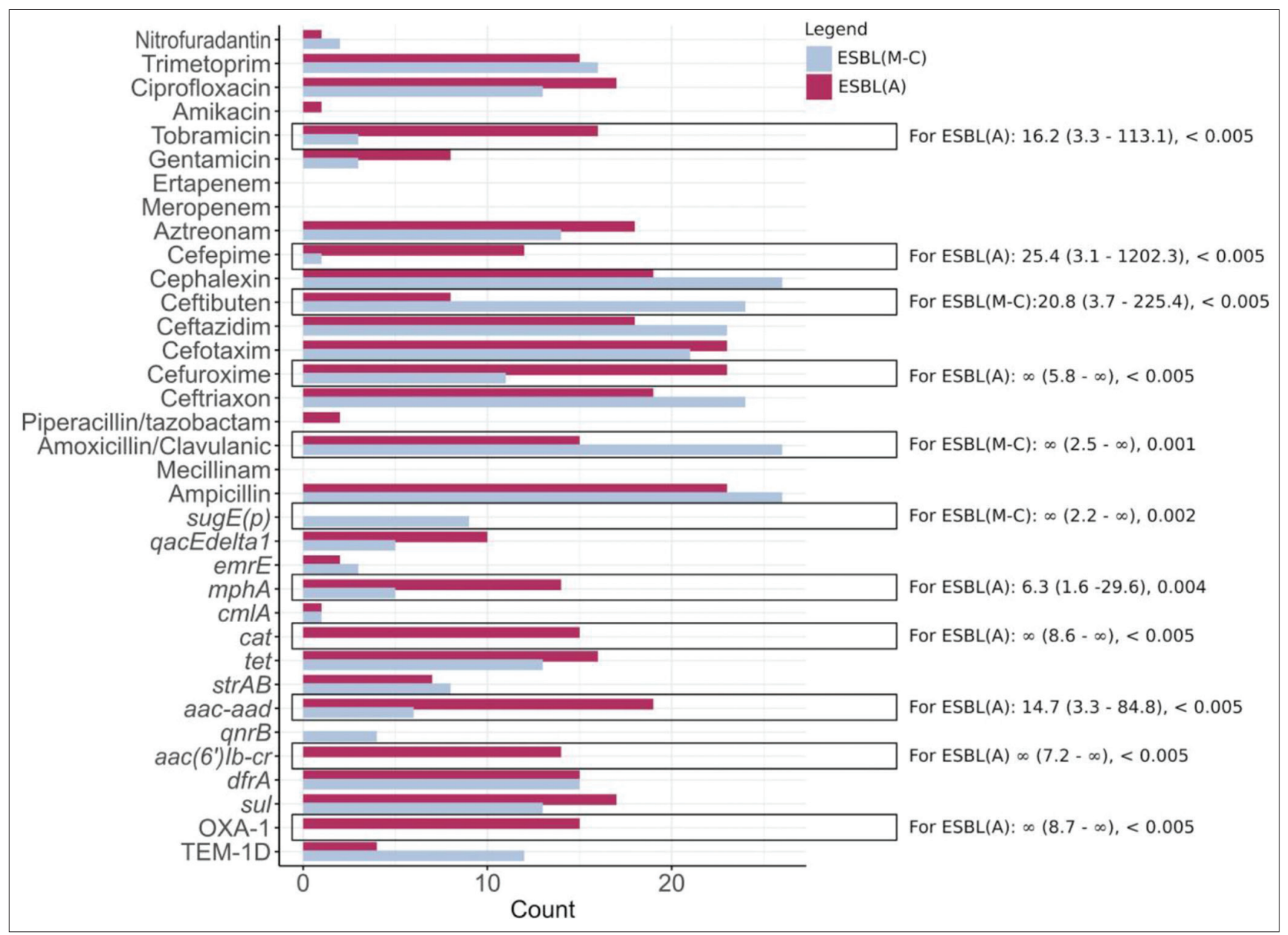

Figure-2: Comparison of $\mathrm{ESBL}_{\mathrm{A}}$ and $\mathrm{ESBL}_{\mathrm{M}-\mathrm{C}}$ for their susceptibility to antibiotics and antimicrobial resistance determinants. Red staples $\mathrm{ESBL}_{\mathrm{A}^{\prime}}$ gray staples $\mathrm{ESBL}_{\mathrm{M}-\mathrm{C}}$, boxes highlight antibiotic resistance or resistance determinants with statistically significant results (odds ratio [95\% confidence interval], probability $\mathrm{p}$ ).

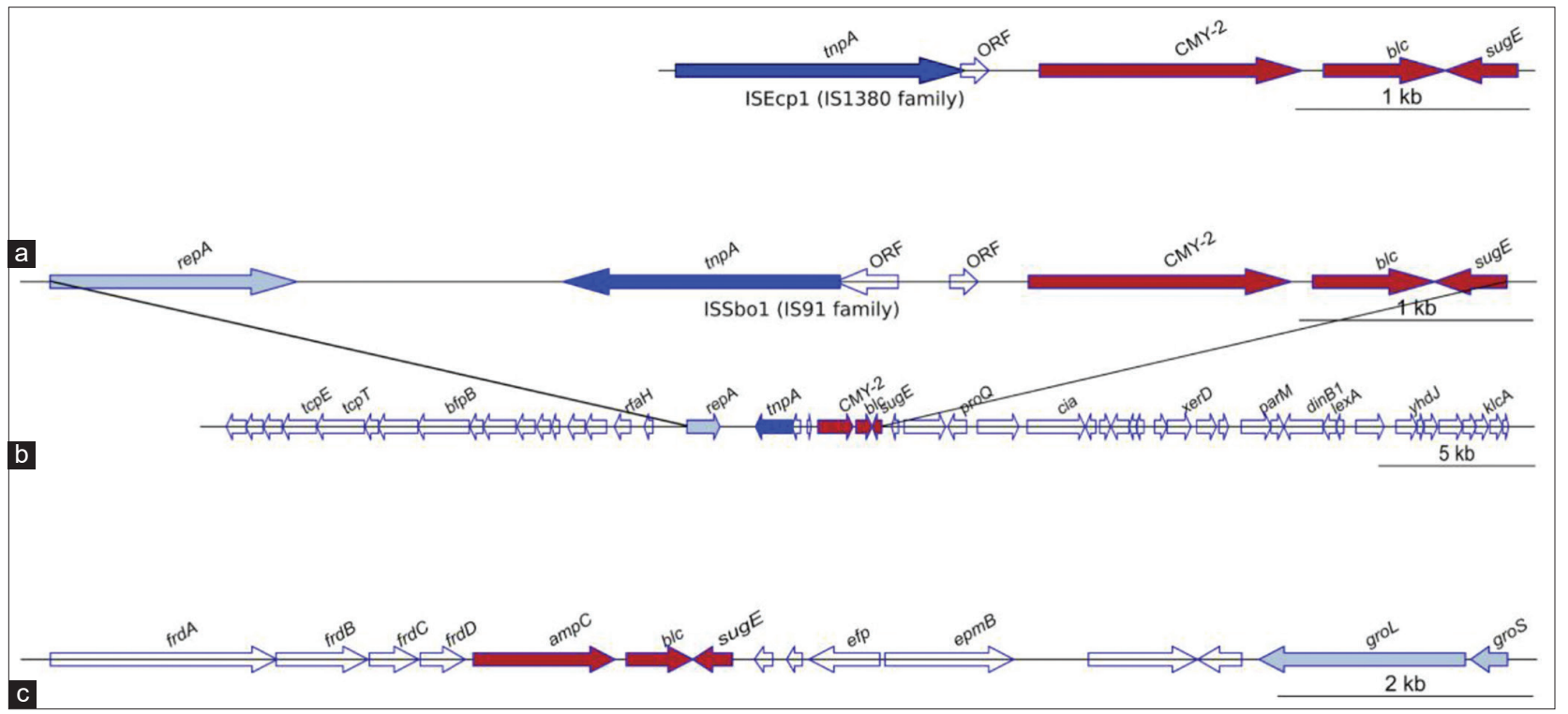

Figure-3: Representative gene synteny of $b a_{C M Y-2}$ with sugE for various isolates in the study. First diagram (a) shows $\operatorname{sugE}(p)$ and $b_{a_{C M Y-2}}$ with its surrounding genes and insertions sequence ISEcp1 (IS1380 family), the second diagram (b) shows the assembly of IncI1 plasmid (below) with bla ${ }_{C M Y-2,} \operatorname{sugE}(p)$, and insertions sequence ISSbo1 (IS91 family), and the third diagram shows a representative genetic environment of chromosomal sugE. 


\section{Discussion}

The present study investigated coresistance to QACs in $\mathrm{ESBL}_{\mathrm{A}}$ - and $\mathrm{ESBL}_{\mathrm{M}-\mathrm{C}}$-producing E. coli isolates. None of the isolates showed increased tolerance to BAC or CTAB and compared to other studies, resistance determinants to QACs were rare. Nonetheless, ESBL $_{\mathrm{M}-\mathrm{C}}$ was associated to the plasmid-borne small multidrug resistance (SMR) efflux pump $\operatorname{sugE}(p)$, while $\mathrm{ESBL}_{\mathrm{A}}$ was mainly associated with other antibiotic resistance determinants that confer resistance to macrolides (mphA), chloramphenicol (cat), aminoglycosides (aac-aad), quinolones aac(6')lb-cr, and beta-lactamases bla $a_{\text {OXA-1 }}$. The different ESBL types were also more frequently harbored by isolates belonging to different phylogroups: $\mathrm{ESBL}_{\mathrm{M}-\mathrm{C}}$ was more often found in none-B2 phylogroups, especially in phylogroups $\mathrm{A}$ and $\mathrm{D}$, while $\mathrm{ESBL}_{\mathrm{A}}$ was frequently found in B2 phylogroup.

Major resistance mechanism to QACs in Gramnegative bacilli is mediated through efflux pumps, where SMR) proteins are known to confer resistance to a variety of QACs. The $\operatorname{sug} E(p)$ has been described to mediate tolerance to a range of antiseptics and other toxic lipophilic compounds [20]. None of the isolates in the study harboring plasmid-borne $\operatorname{sug} E(p)$ genes showed increased MIC values to CTAB or BAC. Chung and Saier [21] showed that overexpression of chromosomally encoded $s u g E$ determinant in $E$. coli does only confer phenotypic tolerance to a narrow spectrum of QACs including CTAB, which, in addition, might be induced by mutants in $s u g E$ leading to hypersensitivity to QACs. It is thereby possible that isolates need selective pressure by QAC exposure to express phenotypic resistance. Still, it is uncertain how additional $s u g E$ genes, gained through horizontal gene transfer, and might give additional benefit to the host organism. Indeed, our findings might be in line with the report of Kermani et al. [22], who found that the primal function of SMR proteins is guanidinium export, and only a limited portion of these proteins mediates multidrug efflux. QACs are heavily used as disinfectants in animal food production, and phenotypic resistance has been measured in exposed isolates from these environments. In contrast, clinical isolates might not be exposed to significant levels of QACs, as these compounds are rather toxic to humans. However, QAC-resistant isolates have been found in hospital environments and have been linked to spreading with significant mortality [12].

It has been suggested that plasmid-borne $\operatorname{sugE}(p)$ genes have been mobilized from $C$. freundii, together with bla $a_{\mathrm{CMY}}$ and the outer membrane lipoprotein Blc, an event that has been hypothesized to happened at least 6 times [23]. However, only nine out of 22 bla ${ }_{\text {СТХ-м }}$-producing E. coli isolates showed the genetic structure $b l a_{\mathrm{CMY}}-b l c-\operatorname{sug} E(p)$, which was accompanied by transposable elements. These genetic elements have been found in a variety of other Enterobacteriaceae, such as Klebsiella oxytoca, Salmonella spp., or Shigella spp. [24]. Curiously, the chromosomal environment of $\operatorname{sugE}(c)$ in E. coli compromises the same genetic structure with $a m p C-b l c-$ sugE, however, no transposon-like element was found close by. Mobilization events are common in bacteria, and species that inhabited soils and wet environments have frequently been the source for antimicrobial resistance determinants causing huge problems in clinical situations [23]. Even though SMR proteins do not seem to transfer measurable tolerance to QACs tested here, they have been associated with increased mobilization and spread of antimicrobial resistance in polluted environments [8].

Once antibiotic resistance determinants have been acquired by human pathogens like $E$. coli, they can successfully spread by clones. $E$. coli belonging to ST131 have emerged during the 2000s as a pandemic, hypervirulent, and multiresistant clone [25]. Isolates that belong to $E$. coli ST131 do often produce $b l a_{\text {CTX-M-15, }}$, which has also been found in the present study: A majority of the bla ${ }_{\text {СТХ-м}}$-producing isolates belonged to ST131. In contrast, for bla $a_{\mathrm{CTX}-\mathrm{M}}$-producing isolates from Uppsala University Hospital, no strong association to a certain clone was observed, the isolates were rather evenly distributed over all phylogenetic groups. So far, bla ${ }_{\mathrm{CMY}}$ enzymes spread mostly polyclonally within $E$. coli, and extensive dissemination was rather linked to mobile genetic elements such as IncI1 plasmids and insertions sequence ISEcp1 [26,27]. For the present collection, $\operatorname{sug} E(p)$ was mainly found in the context of a transposable ISEcp1 element and in one case with an ISSbo1 element that was assembled on an IncI1 plasmid. Chiu et al. [28] showed that blc and $\operatorname{sug} E(p)$ might have a regulatory function for $b l a_{\mathrm{CMY}}$, leading to downregulation or upregulation, respectively.

\section{Conclusion}

Resistance determinants associated with SMR proteins that have been associated to QAC resistance were frequently found in ESBL-producing isolates, although no phenotypic tolerance could be detected. While the biological role of many proteins belonging to the SMR efflux pumps is not elusively clear, their wide spread might indicate other sources for selective pressure than antibiotics.

\section{Authors' Contributions}

$\mathrm{SS}, \mathrm{AH}$, and ET: Conception or design of the work SS and ET: Data collection SS and AH: Data analysis and interpretations.SS and AH: Drafting the article. AH and ET: Critical revision of the article. All authors read and approved the final manuscript.

\section{Acknowledgments}

Susanne Sütterlin holds a grant from Departmental funds Landstinget Uppsala län (ALF funds) (ALF 810901), and Anna Heydecke holds a 
grant from the Center for Research and Development Gävleborg, Uppsala University, Gävle, Sweden. The generation of sequence data was financially supported by a grant from Afa Insurance, Sweden (Grant number 150411) and Alf-de-Ruvo Memorial Foundation, Sweden. The funders had no role in study design, data collection and interpretation, or the decision to submit the work for publication.

\section{Competing Interests} interests.

The authors declare that they have no competing

\section{Publisher's Note}

Veterinary World (Publisher of International Journal of One Health) remains neutral with regard to jurisdictional claims in published institutional affiliation.

\section{References}

1. Dadgostar, P. (2019) Antimicrobial resistance: Implications and costs. Infect. Drug Resist., 12(1): 3903-3910.

2. Nathan, C. and Cars, O. (2014) Antibiotic resistance--problems, progress, and prospects. N. Engl. J. Med., 371(19): 1761-1763.

3. Russell, A.D. (1997) Plasmids and bacterial resistance to biocides. J. Appl. Microbiol., 83(2): 155-165.

4. Bragg, R., Jansen, A., Coetzee, M., van der Westhuizen, W. and Boucher, C. (2014) Bacterial resistance to Quaternary Ammonium Compounds (QAC) disinfectants. Adv. Exp. Med. Biol., 808(1): 1-13.

5. Gerba, C.P. (2015) Quaternary ammonium biocides: Efficacy in application. Appl. Environ. Microbiol., 81(2): 464-469.

6. Kaj, L., Wallberg, P. and Brorström-Lundén, E. (2014) Quaternary ammonium compounds : Analyses in a Nordic cooperation on screening. Available from: https://www.norden.org/en/publication/quaternary-ammonium-compounds. Retrieved on 01-09-2020.

7. Ma, L., Li, A.D., Yin, X.L. and Zhang, T. (2017) The prevalence of integrons as the carrier of antibiotic resistance genes in natural and man-made environments. Environ. Sci. Technol., 51(10): 5721-5728.

8. Ghaly, T.M., Chow, L., Asher, A.J., Waldron, L.S. and Gillings, M.R. (2017) Evolution of class 1 integrons: Mobilization and dispersal via food-borne bacteria. PLoS One, 12(6): e0179169.

9. Jacoby, G.A. (2009) AmpC beta-lactamases. Clin. Microbiol. Rev., 22(1): 161-182.

10. Bevan, E.R., Jones, A.M. and Hawkey, P.M. (2017) Global epidemiology of CTX-M $\beta$-lactamases: Temporal and geographical shifts in genotype. J. Antimicrob. Chemother., 72(8): 2145-2155.

11. Giske, C.G., Sundsfjord, A.S., Kahlmeter, G., Woodford, N., Nordmann, P., Paterson, D.L., Cantón, R. and Walsh, T.R. (2009) Redefining extended-spectrum beta-lactamases: Balancing science and clinical need. J. Antimicrob. Chemother., 63(1): 1-4.

12. Chapuis, A., Amoureux, L., Bador, J., Gavalas, A., Siebor, E., Chrétien, M.L. and Neuwirth, C. (2016) Outbreak of extended-spectrum beta-lactamase producing Enterobacter cloacae with high MICs of Quaternary Ammonium Compounds in a hematology ward associated with contaminated sinks. Front. Microbiol., 7: 1070.

13. Zurfluh, K., Stevens, M.J.A., Stephan, R. and
Nüesch-Inderbinen, M. (2018) Complete and assembled genome sequence of an NDM-5-and CTX-M-15-producing Escherichia coli sequence Type 617 isolated from wastewater in Switzerland. J. Glob. Antimicrob. Resist., 15(1): 105-106.

14. Cantón, R. and Coque, T.M. (2006) The CTX-M beta-lactamase pandemic. Curr. Opin. Microbiol., 9(5): 466-475.

15. Pérez-Pérez, F.J. and Hanson, N.D. (2002) Detection of plasmid-mediated AmpC beta-lactamase genes in clinical isolates by using multiplex PCR. J. Clin. Microbiol., 40(6): 2153-2162.

16. Alikhan, N.F., Zhou, Z., Sergeant, M.J. and Achtman, M. (2018) A genomic overview of the population structure of Salmonella. PLoS Genet., 14(4): e1007261.

17. Jolley, K.A., Bliss, C.M., Bennett, J.S., Bratcher, H.B., Brehony, C., Colles, F.M., Wimalarathna, H., Harrison, O.B., Sheppard, S.K., Cody, A.J. and Maiden, M.C. (2012) Ribosomal multilocus sequence typing: Universal characterization of bacteria from domain to strain. Microbiology, 158(Pt 4): 1005-1015.

18. Ochman, H., and Selander, R.K. (1984) Standard reference strains of Escherichia coli from natural populations. $J$. Bacteriol., 157(2): 690-693.

19. Ciccarelli, F.D., Doerks, T., von Mering, C., Creevey, C.J., Snel, B. and Bork, P. (2006) Toward automatic reconstruction of a highly resolved tree of life. Science, 311(5765): 1283-1287.

20. Zou, L., Meng, J., McDermott, P.F., Wang, F., Yang, Q., Cao, G., Hoffmann, M. and Zhao, S. (2014) Presence of disinfectant resistance genes in Escherichia coli isolated from retail meats in the USA. J. Antimicrob. Chemother., 69(10): 2644-2649.

21. Chung, Y.J. and Saier, M.H. (2002) Overexpression of the Escherichia coli sugE gene confers resistance to a narrow range of quaternary ammonium compounds. J. Bacteriol., 184(9): 2543-2545.

22. Kermani, A.A., Macdonald, C.B., Gundepudi, R. and Stockbridge, R.B. (2018) Guanidinium export is the primal function of SMR family transporters. Proc. Natl. Acad. Sci. U. S. A., 115(12): 3060-3065.

23. Barlow, M. and Hall, B.G. (2002) Origin and evolution of the AmpC beta-lactamases of Citrobacter freundii. Antimicrob. Agents Chemother., 46(5): 1190-1198.

24. Su, L.H., Chen, H.L., Chia, J.H., Liu, S.Y., Chu, C., Wu, T.L. and Chiu, C.H. (2006) Distribution of a transposon-like element carrying bla(CMY-2) among Salmonella and other Enterobacteriaceae. J. Antimicrob. Chemother., 57(3): 424-429.

25. Kondratyeva, K., Salmon-Divon, M. and Navon-Venezia, S. (2020) Meta-analysis of pandemic Escherichia coli ST131 plasmidome proves restricted plasmid-clade associations. Sci. Rep., 10(1): 36

26. Sidjabat, H.E., Seah, K.Y., Coleman, L., Sartor, A., Derrington, P., Heney, C., Faoagalib, J., Nimmoac, G.R. and Paterson, D.L. (2014) Expansive spread of IncI1 plasmids carrying blaCMY-2 amongst Escherichia coli. Int. J. Antimicrob. Agents, 44(3): 203-208.

27. Pietsch, M., Irrgang, A., Roschanski, N., Michael, G.B., Hamprecht, A., Rieber, H., Käsbohrer, A., Schwarz, S., Rösler, U., Kreienbrock, L., Pfeifer, Y., Fuchs, S., Werner, G. and RESET Study Group. (2018) Whole genome analyses of CMY-2-producing Escherichia coli isolates from humans, animals and food in Germany. BMC Genomics, 19(1): 601.

28. Chiu, C.H., Lee, J.J., Wang, M.H. and Chu, C. (2020) Genetic analysis and plasmid-mediated bla ${ }_{\mathrm{CMY}-2}$ in Salmonella and Shigella and the ceftriaxone susceptibility regulated by the ISEcp-1 tnpA-bla ${ }_{\text {CMY-2 }}$-blc-sugE. J. Microbiol. Immunol. Infect., 2020(1): 1-8. 


\section{Supplemental material}

Table-S1: Summary over the nucleic acid sequences included in the sequence analyzes.

\begin{tabular}{|c|c|c|c|c|}
\hline Genes & Function & Accession number & Source & References \\
\hline qacE $\Delta 1$ & $\begin{array}{l}\text { Quaternary ammonium compound } \\
\text { efflux SMR transporter }\end{array}$ & $\begin{array}{l}\text { AF205943, } \\
\text { NG_048042 }\end{array}$ & $\begin{array}{l}\text { R751 (E. coli), } \\
\text { pVS1 ( } P . \text { aeruginosa) }\end{array}$ & {$[1,2]$} \\
\hline qacE & $\begin{array}{l}\text { Quaternary ammonium compound } \\
\text { efflux SMR transporter }\end{array}$ & NG_048041 & R75 (E. aerogenes) & [3] \\
\hline qacF & $\begin{array}{l}\text { Quaternary ammonium compound } \\
\text { efflux (SMR type transporter) }\end{array}$ & NG_051881 & pIP833 (E. aerogenes) & [4] \\
\hline $\operatorname{sug} \mathrm{E}(\mathrm{p})$ & $\begin{array}{l}\text { Multidrug efflux pump } \\
\text { (SMR type transporter) }\end{array}$ & $\begin{array}{l}\text { AY339625, } \\
\text { AY581205 }\end{array}$ & $\begin{array}{l}\text { p541 (E. coli), pIW759 } \\
\text { (S. enterica subsp. enterica, } \\
\text { serovar Typhimurium) }\end{array}$ & {$[5,6]$} \\
\hline emrE ( $\mathrm{mrvC})$ & Multidrug efflux pump (SMR-type) & M62732 & E. coli & {$[7,8]$} \\
\hline to/C & Outer membrane channel & ENA|X54049 & E. coli & [9] \\
\hline $\operatorname{acrR}, \mathrm{A}, \mathrm{B}$ & Multidrug efflux pump, RND family & U00734 & E. coli & {$[10]$} \\
\hline $\operatorname{acrEF}($ envCD) & Multi efflux pump (RND family) & X57948 & E. coli & {$[11]$} \\
\hline emrABR & Multi efflux pump & $\begin{array}{l}\text { M86657, } \\
\text { NC_000913.3, } \\
\text { U19993 }\end{array}$ & E. coli & {$[12,13]$} \\
\hline
\end{tabular}

SMR - small multidrug resistance

Table-S2: Accession numbers of sequence raw data in ENA within project PRJEB17631 and its corresponding isolate ID.

\begin{tabular}{llcc}
\hline ENA & Isolate ID & ENA & Isolate ID \\
\hline ERR1718941 & WTCHG_320308_269190 & ERR1718939 & WTCHG_320308_268190 \\
ERR1718881 & WTCHG_320308_238190 & ERR1718943 & WTCHG_320308_270190 \\
ERR1718885 & WTCHG_320308_240190 & WRR1718945 & WTCHG_320308_271190 \\
ERR1718887 & WTCHG_320308_241190 & ERR1718947 & WTCHG_320308_273190 \\
ERR1718889 & WTCHG_320308_242190 & ERR1718949 & WTCHG_320308_274190 \\
ERR1718891 & WTCHG_320308_243190 & ERR1718951 & WTCHG_320308_275190 \\
ERR1718893 & WTCHG_320308_244190 & ERR1718953 & WTCHG_320308_276190 \\
ERR1718897 & WTCHG_320308_246190 & ERR1718955 & WTCHG_320308_277190 \\
ERR1718899 & WTCHG_320308_247190 & ERR1718957 & WTCHG_320308_278190 \\
ERR1718901 & WTCHG_320308_248190 & ERR1718959 & WTCHG_320308_279190 \\
ERR1718903 & WTCHG_320308_249190 & ERR1718961 & WTCHG_320308_280190 \\
ERR1718905 & WTCHG_320308_250190 & ERR1718963 & WTCHG_320308_281190 \\
ERR1718907 & WTCHG_320308_251190 & ERR1718965 & WTCHG_320308_285190 \\
ERR1718909 & WTCHG_320308_252190 & WRTCHG_320308_286190 \\
ERR1718911 & WTCHG_320308_253190 & ERR1718969 & WTCHG_320308_287190 \\
ERR1718913 & WTCHG_320308_254190 & ERR1718971 & WTCHG_320308_288190 \\
ERR1718915 & WTCHG_320308_255190 & ERR1718975 & WTCHG_320308_291190 \\
ERR1718917 & WTCHG_320308_256190 & ERR1718977 & WTCHG_320308_292190 \\
ERR1718919 & WTCHG_320308_257190 & ERR1718983 & WTCHG_320308_293190 \\
ERR1718921 & WTCHG_320308_258190 & ERR1718985 & WTCHG_320308_295190 \\
ERR1718923 & WTCHG_320308_259190 & ERR1718987 & WTCHG_320308_296190 \\
ERR1718925 & WTCHG_320308_261190 & ERR1718991 & WTCHG_320308_302190 \\
ERR1718927 & WTCHG_320308_262190 & ERR1718993 & WTCHG_320308_303190 \\
ERR1718929 & WTCHG_320308_263190 & ERR1718997 &
\end{tabular}

\section{References}

1. Recchia GD, Stokes HW, Hall RM. Characterisation of specific and secondary recombination sites recognised by the integron DNA integrase. Nucleic Acids Res. 1994 Jun 11;22(11):2071-8.

2. Poirel L, Naas T, Guibert M, Chaibi EB, Labia R, Nordmann P. Molecular and biochemical characterization of VEB-1, a novel class A extended-spectrum beta-lactamase encoded by an Escherichia coli integron gene. Antimicrob Agents Chemother. 1999 Mar;43(3):573-81.

3. Thorsted PB, Macartney DP, Akhtar P, Haines AS, Ali N, Davidson $\mathrm{P}$, et al. Complete sequence of the IncP $\beta$ plasmid R751: implications for evolution and organisation of the IncP backbone. J Mol Biol. 1998 Oct;282(5):969-90.

4. Ploy MC, Courvalin P, Lambert T. Characterization of In40 of Enterobacter aerogenes BM2688, a class 1 integron with two new gene cassettes, cmlA2 and qacF. Antimicrob Agents Chemother. 1998 Oct;42(10):2557-63.

5. Miriagou V, Carattoli A, Tzelepi E, Villa L, Tzouvelekis LS. IS26-associated In4-type integrons forming multiresistance loci in enterobacterial plasmids. Antimicrob Agents Chemother. 2005 Aug;49(8):3541-3.

6. Giles WP, Benson AK, Olson ME, Hutkins RW, Whichard JM, Winokur PL, et al. DNA sequence analysis of regions surrounding bla $_{C M Y-2}$ from multiple Salmonella plasmid backbones. Antimicrob Agents Chemother. 2004 Aug;48(8):2845-52.

7. Morimyo M, Hongo E, Hama-Inaba H, Machida I. Cloning and characterization of the mvrC gene of Escherichia coli $\mathrm{K}-12$ which confers resistance against methyl viologen toxicity. Nucleic Acids Res. 1992 Jun 25;20(12):3159-65. 
8. Yerushalmi H, Lebendiker M, Schuldiner S. EmrE, an Escherichia coli $12-\mathrm{kDa}$ multidrug transporter, exchanges toxic cations and $\mathrm{H}+$ and is soluble in organic solvents. $\mathrm{J}$ Biol Chem. 1995 Mar 24;270(12):6856-63.

9. Niki H, Imamura R, Ogura T, Hiraga S. Nucleotide sequence of the tolC gene of Escherichia coli. Nucleic Acids Res. 1990 Sep 25;18(18):5547.

10. Ma D, Cook DN, Alberti M, Pon NG, Nikaido $\mathrm{H}$, Hearst JE. Molecular cloning and characterization of acrA and acrE genes of Escherichia coli. J Bacteriol. 1993
Oct;175(19):6299-313.

11. Klein JR, Henrich B, Plapp R. Molecular analysis and nucleotide sequence of the envCD operon of Escherichia coli. Mol Gen Genet. 1991 Nov;230(1-2):230-40.

12. Lomovskaya O, Lewis K, Matin A. EmrR is a negative regulator of the Escherichia coli multidrug resistance pump EmrAB. J Bacteriol. 1995 May;177(9):2328-34.

13. Lomovskaya O, Lewis K. emr, an Escherichia coli locus for multidrug resistance. Proc Natl Acad Sci U S A. 1992 Oct;89(19):8938-42.

$* * * * * * * *$ 